\title{
Effective tools to manage biosimilars prescription: The Italian experience
}

\author{
Elisa Guidotti ${ }^{a, *}$, Bruna Vinci ${ }^{b}$, Francesco Attanasio ${ }^{c}$, Federico Vola ${ }^{a}$ \\ ${ }^{a}$ Management and Health Laboratory, Institute of Management and Department EMbeDS, Scuola Superiore Sant'Anna, Pisa, Italy \\ ${ }^{\mathrm{b}}$ Management and Health Laboratory, Institute of Management and Department EMbeDS, Scuola Superiore Sant'Anna; SSFO, Scuola Specializzazione \\ Farmacia Ospedaliera, Università di Pisa, Pisa, Italy \\ ${ }^{c}$ Drugs and Appropriateness Policy Sector, Tuscany Region, Florence, Italy
}

\section{A R T I C L E I N F O}

\section{Article history:}

Available online $\mathrm{xxx}$

\section{Keywords:}

Biosimilar

Uptake

Italy

Policy

Tool

\begin{abstract}
A B S T R A C T
Introduction: Biosimilars represent both a clinical and a financial opportunity. However, low biosimilar penetration has been observed across Europe. Italy has registered a high and increasing biosimilars uptake, but not uniform across regions.

Objectives: The paper aims to describe different managerial tools that can be leveraged to exploit the biosimilars' potential. A focus on Italy and the Tuscany region will be specifically carried out. Furthermore, this research is intended to propose some preliminary considerations about the most effective measures to support biosimilars' uptake.

Methods: This article is based on both desk research and on action research. A desk research was carried out to explore the existing international and national literature on the measures implemented to promote biosimilars' penetration. The action research concerned a longitudinal cooperation project between the Management and Health Laboratory of Scuola Superiore Sant'Anna of Pisa and the Drugs and Appropriateness Policy Sector of Tuscany Region. The activity saw the direct involvement of the Management and Health Laboratory in supporting the regional pharmaceutical governance in managing biosimilars' penetration.

Results: Several demand and supply side policies to foster biosimilar penetration have been implemented both at national and regional levels. In Italy, most regions have adopted specific biosimilar policies at different moments and with heterogeneous contents. The Tuscan Regional Health System implemented three main measures: formal top-down, bottom-up and "mixed" measures. The strategy was effective in increasing biosimilar uptake. The success is probably associated with its comprehensive approach and to the coherence of the different measures it was composed of.
\end{abstract}

(c) 2020 Fellowship of Postgraduate Medicine. Published by Elsevier Ltd. All rights reserved.

\section{Background}

\subsection{The Italian national health system and pharmaceutical care}

The Italian National Health System (INHS) was established in 1978 by following a Beveridge model, with provision of universal coverage largely free of charge at the point of service.

The INHS is in charge of providing pharmaceutical care and accounts for the largest part of total pharmaceutical spending, dis-

* Corresponding author at: Scuola Superiore Sant'Anna, Piazza Martiri della Libertà 33, 56127 Pisa Italy.

E-mail address: elisa.guidotti@santannapisa.it (E. Guidotti). pensing drugs either through hospital or community pharmacies. [1].

Since the early 1990s, legislative reforms have gradually transferred political, administrative, fiscal and financial responsibilities regarding the provision of healthcare from the national government to the twenty Italian regions [2]. The INHS is therefore currently organised and governed according to three institutional levels: national, regional and local. Italian regional health systems are progressively levelling out, but significant heterogeneity emerges in the quality of care they provide, the level of healthcare expenditure and their financial performance [3].

Italy has been harshly hit by the global economic crisis since 2008. Coherently with its three layer-institutional architecture, Italy responded to the crisis through: a) plans and other interven- 
tions devised by the central government; b) actions jointly taken by the national and regional levels of government; and c) initiatives autonomously endorsed by regions.

The economic crisis led the INHS to pay even closer attention to the pharmaceutical sector and contributed to accelerating the reform process. In particular, at the national level, three main tools have been envisaged to support appropriateness: a) the fixation of expenditure caps; b) the introduction of web-based "clinical registries"; c) the adoption of managed entry agreements.

At regional level, policies have been differently devised and implemented across regions, but they have generally entailed: strengthening the direct distribution of pharmaceutical products; centralizing the procurement process; and leveraging managerial tools (such as budgeting and pay for performance), in order to orient prescriptions towards off-patent and/or lower cost medicines.

In particular, reforms were aimed at addressing the challenges brought by a dynamic context, characterized by the entry of new drugs, the expense of biological medicines, and the subsequent arrival of more affordable biosimilar drugs.

\subsection{The "bio-opportunity"}

\subsubsection{Biological and biosimilar medicines}

Italy was the third market by value for biological medicines in Europe in 2018 [4]. The consumption of biological medicines has been constantly growing across the country in the last years, thus, exerting significant pressure on national pharmaceutical spending.

By the time patent portfolios for originator biological medicines were close to expiration, pharmaceutical companies have brought several biosimilar medicines - or "biosimilars" - to the market.

Biosimilars represent both a clinical and a financial opportunity. Evidence acquired over ten years of clinical experience has demonstrated that biosimilar medicines approved in the European Union can be used for all their registered indications as safely and efficaciously as their reference biological medicines [5].

In addition, as a result of patent expiration and scaled-down market authorisation requirements, biosimilar medicines have been commercialised at lower prices than originators [6]. Therefore, biosimilars have widely been reckoned as a solid opportunity for healthcare systems to jointly assure clinical effectiveness and financial sustainability [7].

Despite the potential for increasing patient access to biological medicines and financial sustainability, to date low biosimilar penetration has been observed across Europe [8] and high variations in biosimilars' uptake has emerged among different countries [9].

Italy, compared to the EU5 countries, ranks among the countries with the highest biosimilars uptake, with a steadily increasing trend [9], however biosimilars' penetration is not uniform across Italian regions [10].

The present paper aims to shed some light on the different managerial tools that can be leveraged to exploit biosimilars' clinical and economic potential and drive their penetration. A focus on Italy and the Tuscany region will be specifically carried out. Tuscany represents an interesting case study for three main reasons. First, Tuscany ranks among the best Italian regions in the provision of healthcare services [11]. Second, in the last few years, a strong effort was put in place by the regional government to reform the governance of drugs and control the related expenditure [12]. Third, Tuscany can be considered a first mover in the implementation of policies oriented at fostering biosimilars penetration. This research therefore: (1) investigates the penetration of biosimilars in the Tuscan Regional Health System (TRHS) in 2017; (2) analyzes the 2018 set of managerial tools adopted by the Drugs and Appropriateness Policy Sector in Tuscany to increase biosimilars' penetration; (3) propose some preliminary considerations about the most effective measures to support biosimilars' uptake.

\section{Methods}

This article is based on both desk research and on action research. Concerning the former, an analysis of the existing international and national literature on the measures implemented to promote the penetration of biosimilars was conducted. Furthermore, Italian national and regional biosimilar resolutions were screened. The documents under study were found through keyword searches on the most popular search engines. The keywords used were, respectively: "biosimilar", "policies", "tools", "penetration”, "uptake”.

The action research occurred within the multiannual cooperation project between the Management and Health Laboratory (MeS-Lab) of Scuola Superiore Sant'Anna of Pisa and the Drugs and Appropriateness Policy Sector of the TRHS. MeS-Lab has been actively collaborating with the regional healthcare administration since 2004. The study is the result of a longitudinal action research process: the activity carried out within this collaboration in 2017 and 2018 actually saw the direct involvement of the MeS-Lab in supporting the regional pharmaceutical governance in managing biosimilars' penetration.

At least three key elements distinguish action research from the other empirical approaches: 1) the collection of data and research material that cannot be usually retrieved; 2) the active involvement of researchers in the design of the solution to an organisational problem faced by the host organisation (typically jointly developed with the members of the organisation); 3 ) the evaluation of the jointly developed solutions, typically by teaming up with the members of the host organisation and by supporting the implementation of new solutions. Hence, organisational change (or at least an attempt to accomplish it) is an important output of this kind of study design [13].

Our research was articulated accordingly in three steps. The first step of the collaboration consisted of a quantitative analysis of regional pharmaceutical administrative flows to detect the most relevant molecules in economic terms (total expenditure). Secondly, the level of biosimilars' penetration for these molecules in Tuscany in 2017 was computed. This was the precondition for the Tuscan Drugs and Appropriateness Policy Sector to design and implement a pay for performance system, addressed to the regional health authorities. MeS-Lab's researchers were involved in providing both data to define the most appropriate targets and expertise for fine-tuning the individual goals [14]. In the final step, a set of indicators on the penetration of the aforementioned molecules was used to benchmark the 2017-2018 trend of biosimilar penetration in Tuscany versus other regions (pre-, post- and cross-sectional comparison), so as to provide a preliminary evaluation of the effectiveness of the different 2018 Tuscan governance actions and to suggest the most appropriate managerial tools to support biosimilars' penetration. Data were processed using SAS®, version 9.4.

\section{Results}

\subsection{Surfing the bio-wave: tools to foster biosimilars' prescriptions}

European governments have designed and implemented specific policies to enhance the use of biosimilars. Differences exist in the pricing and reimbursement procedures, levels of education, characteristics of covered population, and incentivisation of stakeholders (physicians, pharmacists or patients), leading to variations in uptake and divergences in savings from biosimilars use across Europe, and even within the same country $[15,16]$.

By considering one framework [17], policies concerning biosimilars can be divided into "demand-side" and "supply-side" ones. Demand-side measures aim to steer the prescription of biological drugs towards the biosimilar alternative, while supply-side policies focus on the conditions associated with provision of the product. 
Among the demand-side policies, a group of measures deserve particular attention. Several countries have introduced prescription budgets or quotas for biosimilars. A still little diffused policy concerning biosimilars is "automatic substitution", that only few countries permit (Estonia, France, Latvia, Poland, Russia) [18]. Finally, educational policies have spread across countries, such as the drafting of prescribing and clinical guidelines for physicians, the organisation of scientific conferences, seminars and lectures on the theme of biosimilars to inform different stakeholders and trigger biosimilars adoption [15].

Supply-side policies are multiple and range from reference pricing - both internal and external (Italy adopts external reference pricing) - to tendering.

Coherently with its double-layered institutional governance, Italy has devised two different sets of policies at national and regional levels. For the national level, both the demand side and supply side policies have been recently implemented.

Regarding the former, the Italian Medicines Agency (AIFA) has recently published two position papers on biosimilars, to inform healthcare professionals and citizens about biologic and biosimilar medicines and to support interchangeability [19-21]

As for national supply side policies, national pricing and reimbursement policies provide that biosimilars are automatically placed in the same reimbursement class as the reference medicine when the price proposed by the company is of 'obvious convenience' (with no price negotiation between the Company and AIFA) and that, when the negotiation occurs, the price of a biosimilar has to be set at a value at least $20 \%$ lower than the originator's [22].

Regions do not differ in prescription or indication restrictions concerning biological medicines: they operate uniformly, by complying with the national guidelines and the indications of the Italian Medicines Agency (AIFA). Nevertheless, most regions have recently implemented a range of managerial tools specifically aimed at steering biosimilars' uptake. They were adopted at different moments and with heterogeneous content, both leveraging demand side and supply side measures. Campania Region, in November 2009 , legislated on the use of biosimilars, pushing for the choice of biosimilars as first treatment for new patients. In 2010, Veneto published the Guidelines for the use and purchase of biosimilars [23]. In line, the region released three decrees numbered 331/2015 [24], 90/2017 [25] and 112/2018 [26] aimed at improving knowledge on biosimilars and providing information about their safety and efficacy. Since 2011, Friuli Venezia Giulia started implementing multiple incentives for biosimilars prescriptions. Specific protocols were adopted at the Area Vasta level (i.e. the entity appointed to coordinate LHAs and THs actions in a geographical area); furthermore, prescription quotas for newly diagnosed patients were fixed ("drug naive") [27,28]. In 2014, Basilicata, Calabria, Puglia and Sicilia Region legislated on the importance of preferring biosimilars to the originators in naïve patients when economically viable [2932].

Coherently with the previously outlined institutional structure, the Italian national level has therefore defined the framework concerning demand side (leveraging informative policies) and the supply side approaches (by setting the legislative framework). Regions have heterogeneously inflected in the national framework by better specifying and contextualizing the national indications (see for instance Campania's focus on naïve patients, or the Veneto informative decrees), or by complementing the national framework with managerial tools, such as incentives' schemes or prescription quotas (e.g., Friuli Venezia Giulia).

Assessing the correlation between the adoption of specific policies and the penetration levels still seems premature and requires some caution. Some studies attempt to correlate the adoption of different national policies with different levels of biosimilars' uptake. Several factors have been reported as potential drivers of biosimilar uptake and might explain the differences observed between EU member states: i.e., physician and patient adoption of biosimilars, national healthcare systems specificities in terms of pricing, reimbursement, and procurement policies [33]. Policies aimed at solely granting price reductions do not seem to strongly favor biosimilars' uptake [16,34]. Substitution was indicated as a key potential driver of biosimilar uptake, though this could be prevented if there are limited outcomes. Thus, the suggestion is to adopt and evaluate such a policy when strong biosimilar realworld evidence is available [35]. Education initiatives (addressed to physicians and patients), competition-driven pricing policies, the introduction of incentives or quotas was recommended to improve biosimilars' uptake, although based on qualitative judgments by selected stakeholders [15].

Rèmuzat and colleagues used a quantitative approach to demonstrate that:

- biosimilar price discount over original biologic price, the number of analogues, and the distribution channel were not correlated with the biosimilar uptake;

- average generic price discount over originator and the number of biosimilars show a trend toward statistical significance for correlation with biosimilar uptake, but do not reach the significance threshold;

- incentive policies and the date of first biosimilar market entry were correlated with biosimilar uptake [17], although other studies suggested that incentives might differently impact product classes [36].

Concerning Italy, it has been suggested that those regions that first have established policies to promote the entry of biosimilars into the therapeutic plans have recorded a high penetration rate; on the contrary, those regions that have drawn up late and unfocused policies seem to have experienced a low penetration of biosimilars [4].

However, these findings refer to policies implemented at national/regional level and related outcomes, disregarding the local context. They do not inquire about the effectiveness of managerial strategies designed at local level; they miss local policy environments; and they do not appropriately account for the interactions among the different stakeholders at the organisational level [15].

Given the multilevel organisation of the INHS [37] and the relevance of policies adopted at regional level, it is important to focus on the analysis of those managerial tools regions have adopted to foster biosimilar penetration and to conduct preliminary evaluations of the results reached.

\subsection{Focus on the Tuscany region}

\subsubsection{Analysis of regional pharmaceutical administrative flows}

The analysis considered patent-expired medicines whose biosimilar first marketing date occurred before December 2017. Specifically, Epoetin, Etanercept, Filgrastim, Follitropin alfa, Infliximab, Insulin Glargine, Rituximab, Somatropin were considered. Rituximab, Etanercept, Somatropin and Epoetin were chosen as objects of the study since they emerged as the most expensive for the Tuscan Regional Health System (TRHS) in 2017.

High heterogeneity in biosimilar penetration was identified for these medicines in Tuscany in 2017. The percentage of biosimilar Rituximab was 7,10\%, calculated as milligrams of biosimilar Rituximab administered in 2017 divided by total milligrams of Rituximab-based drugs administered that year. In the specific case of Rituximab, the calculation was carried out in milligrams since some of the administrative flows did not present the link between the drug administered and the anonymised user ID. For the other medicines, the chosen unit of calculation was the number of patients. The percentage of biosimilar Etanercept was 21,05\%. The 


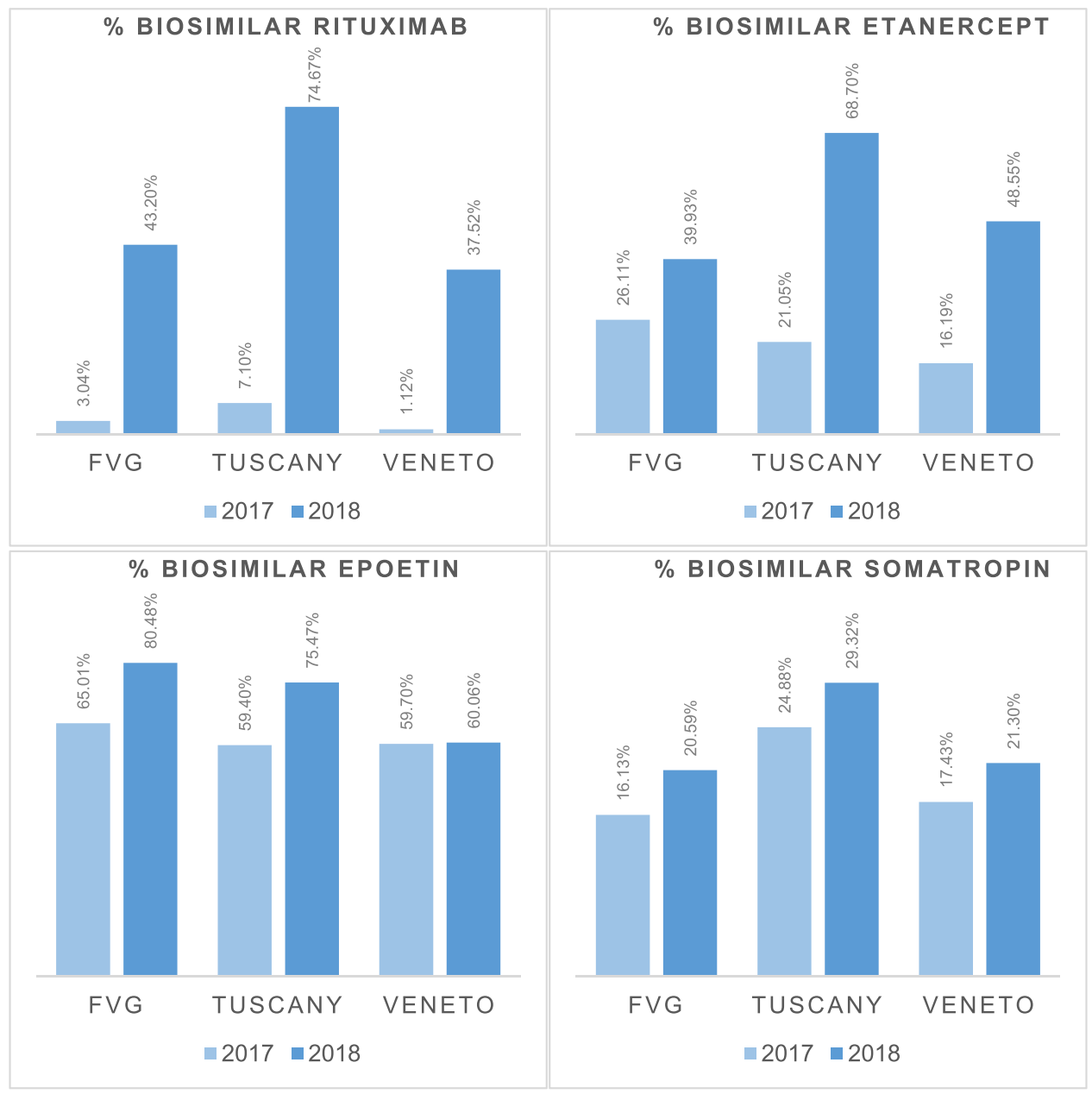

Fig. 1. Inter-regional geographic variation - Friuli Venezia Giulia (FVG), Tuscany, Veneto

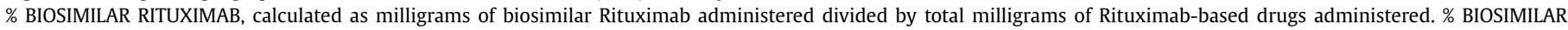

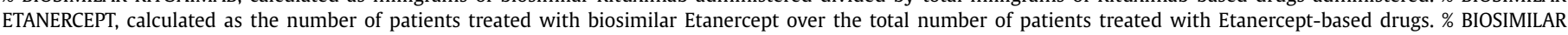

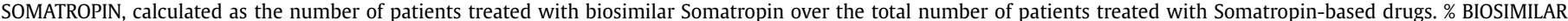
EPOETIN, calculated as the number of patients treated with biosimilar Epoetin over the total number of patients treated with Epoetin-based drugs.

Source: http://performance.sssup.it/network.

percentage of biosimilar Somatropin was $24,88 \%$. Greater biosimilar penetration was recorded for Epoetin (59,40\%) (see Fig. 1).

\subsubsection{Analysis of regional resolutions and other governance tools}

Biosimilars penetration has been the main cornerstone of the 2018 drug governance policy of the TRHS. For this purpose, the MeS-Lab researchers supported the TRHS in designing a comprehensive strategy that included both top-down and bottom-up managerial tools.

Concerning the former, a regional resolution specifically aimed at fostering the biosimilars' uptake was issued. Resolution $n^{\circ} 194 / 2018$, dated $26^{\text {th }}$ February 2018, provided that Tuscan healthcare organizations could not ask for and use products other than those awarded through a tender by the regional procurement body (ESTAR). Furthermore, those requests of drugs not subjected to ESTAR tendering procedures had to be treated at regional level through a careful evaluation run by the Drugs and Appropriateness Policy Sector [38]. In the case of the molecules analyzed, if a biosimilar was awarded the tender, doctors were asked to prescribe the biosimilar. The use of an originator, in such a situation, became subjected to the evaluation and approval of the TRHS.

The resolution was accompanied by bottom-up measures. The Drugs and Appropriateness Policy Sector, supported by MeS-Lab, activated an engagement process with managers and specialists of Tuscan LHAs and Teaching Hospitals (THs) to open a debate on the use of biosimilars and to define shared targets for increasing their uptake. More specifically, two monthly meetings with chief medical officers of all the Tuscan LHAs with a focus on pharmaceuticals, one monthly gathering with directors of pharmaceutical services and one monthly focus on pharmaceutical expenditure during budget revisions with chief executive officers were organised throughout 2018, to discuss the level of biosimilar penetration in different structures, monitor the achievements, benchmark providers against each other, and revise the targets.

Third, this comprehensive strategy included a "mixed-side" approach, that combined some top-down elements with bottom-up ones: the level of biosimilars' penetration in Tuscany in 2017 was computed and this was the precondition for the Tuscan Drugs and Appropriateness Policy Sector to design and implement a pay for performance system, addressed to the regional health authorities. MeS-Lab's researchers were involved in providing both data to define the most appropriate targets, and expertise in fine-tuning the individual goals. In the final step, a set of indicators on the penetration of the aforementioned molecules was designed and computed, so as to benchmark the 2017-2018 trend of biosimilar penetration in Tuscany versus other regions (pre-, post- and crosssectional comparison). 


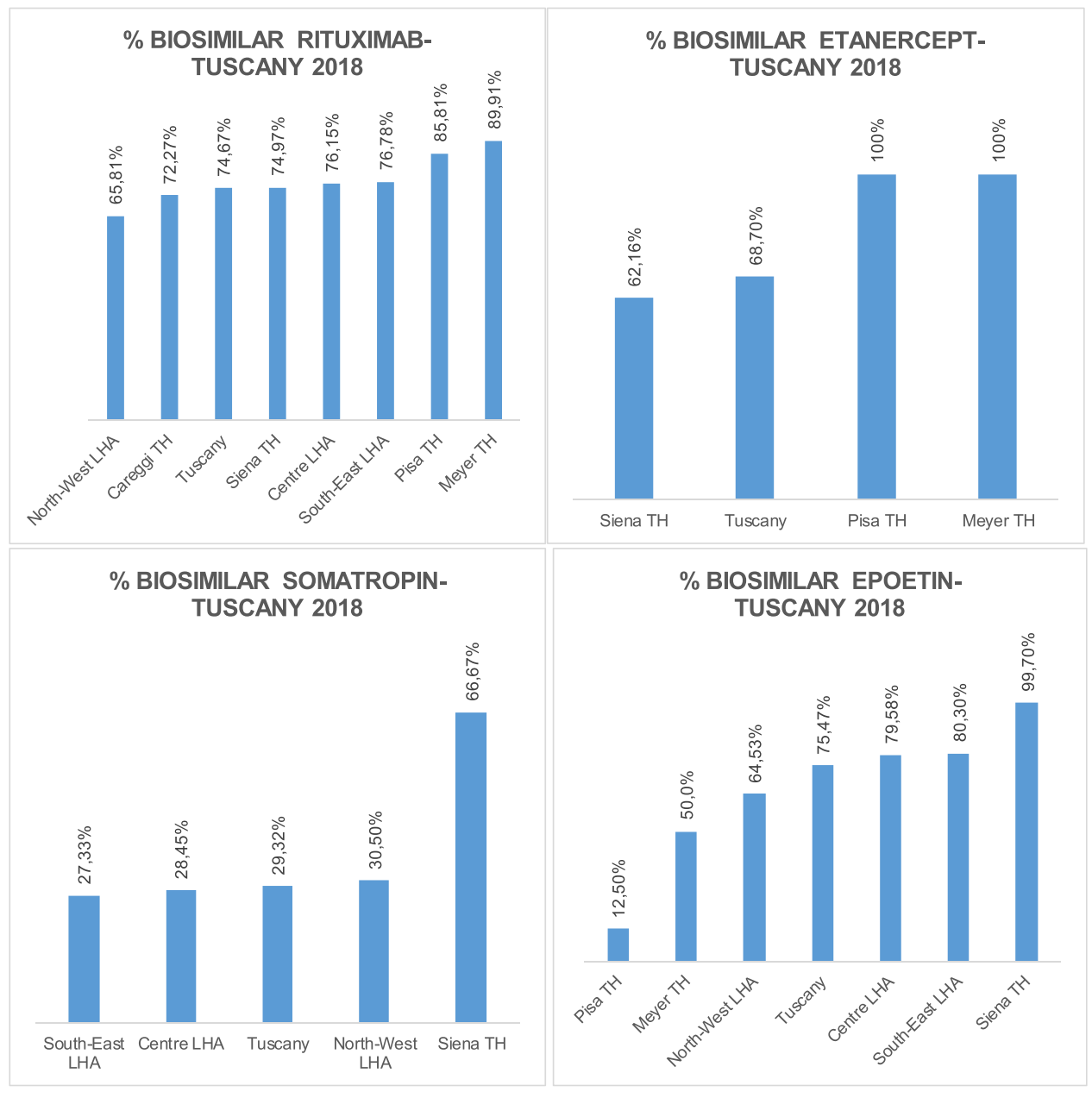

Fig. 2. Intra-regional geographic variation, Tuscany 2018. Source: http://performance.sssup.it/network.

\subsubsection{Preliminary evaluation - 2017-2018 penetration trends}

The high heterogeneity in biosimilars' penetration we identified in Tuscany in 2017 clearly relates to timing in their availability. However, biosimilars' market entry is equally granted at national scale and comparisons among regions offer nevertheless interesting insights concerning the effects of the implementation of different managerial tools, at regional scale. Biosimilar penetration increased for all four molecules over the 2017-2018 period in Tuscany. The percentage of biosimilar Rituximab grew tenfold from $7,10 \%$ in 2017 to $74,67 \%$ in 2018 . The percentage of biosimilar Etanercept reached $68,70 \%$, the percentage of biosimilar Somatropin $29,32 \%$ and the percentage of biosimilar Epoetin $75,47 \%$.

Furthermore, when comparing with other regions that are part of the Italian Regional Performance Evaluation System (IRPES), a Performance Measurement System developed in 2004 by the MeSLab jointly with the TRHS and eleven other Italian Regions [39], showed that Tuscany has registered an increase either higher or in line with other regions. The percentage of biosimilar Rituximab had a remarkable rate of $67,57 \%$, greater Veneto's of $36,4 \%$ and Friuli Venezia Giulia's (FVG) 40,16\%. Biosimilar Etanercept registered a significant increase with a growth in penetration of $47,65 \%$, far higher than observed for Veneto and FVG. The percentage of biosimilar Somatropin and Epoetin registered a growth in line with that of the other regions. The graph below reports 20172018 penetration trends for the IRPES regions that decided to upload their data according to a common calculation methodology (see Fig. 1).
A significant intra-regional geographic variation was observed. The penetration of the same biosimilar varied greatly across different Tuscan LHAs and THs. The percentage of Biosimilar Rituximab in 2018 varied from 65,81\% in North-West LHA to 89,91\% in Meyer $\mathrm{TH}$; the percentage of biosimilar Etanercept from $62,16 \%$ in Siena $\mathrm{TH}$ to $100 \%$ in Pisa $\mathrm{TH}$; the percentage of biosimilar Somatropin from $27,33 \%$ in South-East LHA to $66,67 \%$ in Siena $\mathrm{TH}$; the percentage of biosimilar Epoetin in 2018 Epoetin from 12,50\% in Pisa $\mathrm{TH}$ to $99,70 \%$ in Siena TH (see Fig. 2). Data are shown for those LHAs and THs that used biosimilars in 2018.

\section{Discussion}

Italian health authorities are increasingly focusing on implementing pharmaceutical cost-containment policies, since pharmaceutical expenditure has increased at a rapid pace over the last years and has significantly impacted countries' total healthcare expenditures [8]. Italy has progressively moved towards the reform of the pharmaceutical sector [7]. The reform process has required new tools to manage innovation and guarantee economic sustainability. Most Italian regions have implemented ad-hoc biosimilar policies, though these are different both in terms of content and time of adoption. Tuscany, Veneto and FVG are among those regions that have first moved to promote biosimilars' uptake. While Veneto focused on the progressive adoption of guidelines to foster population knowledge on biosimilars [24,25], FVG adopted mixed 
tools, such as prescription quotas and shared protocols [27,28]. The Drugs and Appropriateness Policy Sector of the TRHS adopted biosimilar policies designed as elements of a coherent strategy, grounded on three pillars: a) top-down formal measures (regional resolutions); b) bottom-up measures (meetings to foster professional engagement); c) "mixed" measures (benchmarking and pay for performance mechanisms).

Since the strategy is intrinsically intertwined, it has proved challenging to disentangle the effects of each single approach and their interactions. Nevertheless, the strategy's effectiveness could be associated with its comprehensive approach in the following ways:

1) the "three-pillar" strategy that involved two of the main stakeholders in steering the prescribing choices: not only managers, but professionals themselves were targeted, to align their objectives with the region's. This approach is coherent with the determinants associated with biosimilars' penetration, where the prescribers' role is pivotal. The appropriate combination of demand-side and supply-side policies might be the preeminent reason explaining the Tuscan success;

2) by combining top-down and bottom-up measures, the Tuscan strategy jointly leveraged extrinsic and intrinsic motivation [40]. It might be suggested that the formal resolutions offered an extrinsic legitimisation, while systematic benchmarking and informal meetings fostered professional engagement and peer pressure, by leveraging internal motivation;

3) the institutional cohesion between regional and national actions. The AIFA position papers offered the legitimisation that the Italian regions needed to fully exploit the biosimilars' opportunity and Tuscany was one of the first regions to seize an alliance at the national level.

Two final considerations may deserve some attention. Firstly, the Tuscan strategy entailed an overarching approach that indiscriminately targeted all biosimilars, regardless of their therapeutic area. Since they refer to a wide range of clinical treatments, prescribers refer to different disciplines (e.g., hematology, oncology, immunology, nephrology). It interesting to underline that the biosimilars' penetration in Tuscany outpaced the other regions, regardless of the clinical specialty. A transversal alliance occurred that transcended clinical boundaries.

On the other side, intra-regional variation is significant and may suggest some considerations concerning the prescribing processes. As an example, while Siena TH registers low penetration regarding biosimilar Etanercept, it represents a best practice with regards to Epoetin and Somatropin (see Fig. 2). This fluctuating performance may suggest that final results do not simply originate from the implementation of external measures, but rather derive from the professional response to it. Intra-regional variation may relate to different areas of expertise of different centers examined (i.e., there are areas of expertise such as rheumatology were biosimilar prescription constitutes a major topical issue [41]) and different casemix. On the other hand, inter-regional variation may be reasonably associated to different policies implemented.

Prescribing behaviors seem to result from a triadic interaction between the regional regulator (that sets the prescribing framework by mediating between the general context and the regional characteristics), clinicians (who mediate between the regional framework and the singularity of each patient) and local managers (who are in charge of mediating between the potentially diverging interests of the other two stakeholders). The success of any governance measure seems to depend on its ability to balance the interactions between these three stakeholders.

\section{Conclusions}

The preliminary lesson that can be drawn from the Tuscan case seems to suggest that the design of specific policies aimed at steering the current prescribing behaviors by overcoming the classical approaches needs to grant a "triple coherence":

- an institutional coherence, between the regulators (national, regional and local ones),

- a motivational coherence, between the main stakeholders (the regional administrators, the managers and the clinicians),

- an instrumental coherence, between the measures that can be leveraged (top-down, bottom up, mixed ones), so as to carefully balancing internal and external motivation.

As a limitation, our research mainly focused on one region and data benchmarking was carried out within a limited number of Italian regions. A quantitative approach to assess the correlation between policy adoption and biosimilars' penetration seemed premature. Furthermore, the MeS-Lab does not access the same data for all the regions, thus a complete evaluation of the inter-regional avoidable variation and of the North-South gradient was not possible. Third, our paper was specifically aimed at inferring some considerations concerning potential effects of different regional policies on biosimilars' uptake: it did not analyze any potential effects on appropriateness. A wider prescribing of biosimilars might be associated to potential inappropriate behaviors, such as first-line prescription of medicines rather recommended as second-line treatments. However, this goes beyond the scope of our study and will be examined in further research.

\section{Author statement}

Elisa Guidotti wrote the paper togheter with Federico Vola. Federico Vola had a foundamental role in defining the methology and supervising the entire work. Elisa Guidotti and Bruna Vinci were responsible for conceptualization, data collection, data curation and formal analysis. Francesco Attanasio, Bruna Vinci, Elisa Guidotti and Federico Vola have been part of the action research process that occurred between the Drug and Appropriateness Sector of the Tuscan Regional Health System and the Management and Health Laboratory of Scuola Superiore Sant'Anna of Pisa.

\section{Ethical approval}

Not required

\section{Funding}

None.

\section{Declaration of Competing Interest}

None declared

\section{Acknowledgements}

This study was supported by the Italian Regional Performance Evaluation System (IRPES) steered by Laboratorio Management e Sanità, Institute of Management, Scuola Superiore Sant'Anna Pisa (Italy). The authors acknowledge Professor Sabina Nuti and all the researchers from Laboratorio Management e Sanità, Institute of Management, Scuola Superiore Sant'Anna, for their constant support and useful comments. 


\section{References}

[1] Ferre F, de Belvis AGI, Valerio L, Longhi S, Lazzari A, Fattore G, et al. Italy: health system review. Health Syst Transit 2014;16(4):1-168.

[2] Ferré F, Noto G, Vola F. O sistema de saúde Italiano e a crise: uma visão geral das políticas e sua implementação. An Inst Hig Med Trop (Lisb) $2018 ; 17(1): 47-58$

[3] France G, Taroni F, Donatini A. The Italian health-care system. Health Econ 2005;14(SUPPL. 1):187-202.

[4] IQVIA. Farmaci biologici e biosimilari - Scenari terapeutici e stima del risparmio per il Sistema Sanitario Italiano [internet]. [cited 2020 May 12]. Available from: http://magazine.imshealth.it/report/(IQVIA)_Farmaci_biologici_ e_biosimilari.pdf.

[5] European Commission \& European Medicines Agency (EMA). Biosimilars in the EU - information guide for healthcare professionals [internet]. [cited 2020 May 12]. p. 395-411. Available from: https://www.ema.europa.eu/en/documents/ leaflet/biosimilars-eu-information-guide-healthcare-professionals_en.pdf.

[6] Farfan-Portet MI, Gerkens S, Lepage-Nefkens I, Vinck I, Hulstaert F. Are biosimilars the next tool to guarantee cost-containment for pharmaceutical expenditures? Eur J Heal Econ 2014;15(3):223-8.

[7] Bria E, Conte P. Biosimilars as a strategy to improve sustainability. ESMO Open 2017;2(May(2)):e000192.

[8] European Commission Organisation for Economic Co-operation and Development (OECD). Health at a Glance: Europe 2018. 2018.

[9] IQVIA. Advancing biosimilar sustainability in Europe - a multi-stakeholder assessment. 2018;(September):40.

[10] Agenzia Italiana del Farmaco (AIFA). Monitoraggio consumi e spesa biosimilari [Internet]. [cited 2020 May 12]. Available from: https://www.aifa.gov.it/ monitoraggio-consumi-e-spesa-biosimilari.

[11] Ministero della SaluteMonitoraggio dei LEA attraverso la cd. Griglia LEA 2017.

[12] Fantini MP, Nuti S, Vola F. Il Governo Dell'innovazione Farmaceutica in Italia. Dallo Stato Dell'arte a Un Modello Di Gestione Regionale Equa e Sostenibile Dei Farmaci Innovativi e Ad Alto Costo. Del Gallo Editore 2016.

[13] Kasanen E, Lukka K. The constructive approach in management accounting research. J Manag Account Res 1993(5):243-64.

[14] Vainieri M, Vola F, Gomez Soriano G, Nuti S. How to set challenging goals and conduct fair evaluation in regional public health systems. Insights from Valencia and Tuscany regions. Health Policy (New York) [Internet]. 2016;120(11):1270-8. Available from http://dx.doi.org/10.1016/j. healthpol.2016.09.011.

[15] Moorkens E, Vulto AG, Huys I, Dylst P, Godman B, Keuerleber S, et al. Policies for biosimilar uptake in Europe: an overview. PLoS One 2017;12(12):1-17.

[16] IMS Institute for Healthcare InformaticsThe impact of biosimilar competition [internet]. IMS Inst Healthc Inf 2016. [cited 2020 May 12]. p. 1-29Available from http://www.medicinesforeurope.com/docs/ IMS-Impact-of-Biosimilar-Competition-2016.pdf.

[17] Rémuzat C, Kapuśniak A, Caban A, Ionescu D, Radière G, Mendoza C, et al. Supply-side and demand-side policies for biosimilars: an overview in 10 European member states. J Mark Access Heal Policy 2017;5(1):1307315.

[18] European Medicines Agency (EMA). Biosimilar medicines: Overview [Internet]. [cited 2020 May 12]. Available from: https://www.ema.europa.eu/en/ human-regulatory/overview/biosimilar-medicines-overview.

[19] Agenzia Italiana del Farmaco (AIFA). Position paper : i farmaci biosimilari [Internet]. 2013 [cited 2020 May 12]. p. 1-15. Available from: http://www.agenziafarmaco.gov.it/sites/default/files/AIFA_POSITION_PAPER_ FARMACI_BIOSIMILARI.pdf.

[20] Agenzia Italiana del Farmaco (AIFA)Secondo position paper AIFA sui Farmaci biosimilari [Internet]. Aifa 2018. [cited 2020 May 12]. p. 128. Available from: http://www.agenziafarmaco.gov.it/sites/default/files/ 2_Position-Paper-AIFA-Farmaci-Biosimilari.pdf.

[21] European Commission. What you need to know about biosimilar medicinal products [Internet]. [cited 2020 May 12]. Available from: file://10.90.0.9/laboratorio/PhD/Guidotti/Articolo Biosimilari/Letteratura/What you Need to Know about Biosimilar Medicinal Products .pdf.
[22] Gazzetta Ufficiale della Repubblica Italiana. DELIBERAZIONE 1 febbraio 2001 [Internet]. 2001 [cited 2020 May 12]. Available from: https://www. gazzettaufficiale.it/eli/id/2001/03/28/001A3188/sg.

[23] Ingrasciotta Y, Giorgianni F, Bolcato J, Chinellato A, Pirolo R, Tari DU, et al. How much are biosimilars used in clinical practice? a retrospective italian population-based study of erythropoiesis-stimulating agents in the years 2009-2013. BioDrugs 2015;29(4):275-84.

[24] Regione del VenetoAllegato A al Decreto n. 16 del 29/06/2010 2015;17:1-17.

[25] Regione del Veneto. Regione del Veneto Coordinamento Regionale Unico sul Farmaco - CRUF: Linee di indirizzo regionali per l'impiego dei farmaci intravitreali per la cura della degenerazione maculare senile [internet]. 2017 [cited 2020 May 12]. p. 1-17. Available from: https://www.regione.veneto.it/c/document_library/get_file?uuid= dd94d7e8-230f-46a7-8937-5d8f35c4eb7e\&groupId=10793.

[26] Regione del Veneto. Decreto n.112 del 13 settembre 2018_Biosimilari.pdf.

[27] Regione Friuli Venezia Giulia. Programma preventivo consolidato 2012 del Servizio Sanitario Regionale. 2012 (May).

[28] Regione Friuli Venezia Giulia. Programma preventivo consolidato 2016 del servizio sanitario regionale. 2016.

[29] IRCSS CROB - Regione Basilicata. Farmaci Biosimilari - Direttiva Vincolante [internet]. [cited 2020 May 12]. Available from: http://www.crob.it/crob/files/ docs/11/20/41/DOCUMENT_FILE_112041.pdf.

[30] Regione Calabria. DPGR - CA n. 37 del 21 Marzo 2014 [internet]. 2014 [cited 2020 May 12]. Available from: http://old.regione.calabria.it/sanita/allegati/ dpgr_2014/d.p.g.r._n._37_del_21.03.2014.pdf.

[31] Regione Puglia. DELIBERAZIONE DELLA GIUNTA REGIONALE 26 febbraio 2014, n. 216 [Internet]. 2014 [cited 2020 May 12]. Available from: http://www. quotidianosanita.it/allegati/allegato2190575.pdf.

[32] Regione Sicilia. Misure volte a promuovere l'utilizzo dei Farmaci Originatori o Biosimilari a minor costo di terapia [Internet]. 2014 [cited 2020 May 12]. Available from: http://pti.regione.sicilia.it/portal/page/ portal/PIR_PORTALE/PIR_LaStrutturaRegionale/PIR_AssessoratoSalute/ PIR_Infoedocumenti/PIR_DecretiAssessratoSalute/PIR_Decreti/PIR_Decreti2014/ PIR_Provvedimentiorganiindirizzopolitico/Decreto sull'utilizzo dei farma.

[33] Renwick MJ, Smolina K, Gladstone EJ, Weymann D, Morgan SG. Postmarket policy considerations for biosimilar oncology drugs. Lancet Oncol [Internet] 2016;17(1):e31-8 Available from:. doi:10.1016/S1470-2045(15)00381-2.

[34] Bocquet F, Paubel P, Fusier I, Cordonnier AL, Sinègre M, Le Pen C. Biosimilar versus patented erythropoietins: learning from 5 years of European and Japanese experience. Appl Health Econ Health Policy 2015;13(1):47-59.

[35] Mestre-Ferrandiz J, Towse A, Berdud M. Biosimilars: how can payers get long-term savings? Pharmacoeconomics 2016;34(6):609-16.

[36] Bocquet F, Paubel P, Fusier I, Cordonnier AL, Le Pen C, Sinègre M. Biosimilar granulocyte colony-stimulating factor uptakes in the EU-5 markets: a descriptive analysis. Appl Health Econ Health Policy 2014;12(3):315-26.

[37] De Rosis S, Guidotti E, Zuccarino S, Venturi G, Ferre' F. Waiting time information in the Italian NHS: A citizen perspective. HEALTH POLICY 2020. doi:10.1016/j.healthpol.2020.05.012.

[38] Regione Toscana - Uffici Regionali Giunta Regionale. Delibera n¹94/2018 [internet]. Vol. 2016. 2016 [cited 2020 May 12]. p. 1-5. Available from: https://www.regione.toscana.it/bancadati/atti/Contenuto.xml?id= 5173900\&nomeFile=Delibera_n.194_del_26-02-2018.

[39] Nuti S, Noto G, Vola F, Vainieri M. Let's play the patients music: a new generation of performance measurement systems in healthcare. Manag Decis 2018;56(10):2252-72.

[40] Benabou R, Tirole J. Intrinsic and extrinsic motivation. Rev Econ Stud 2003;70:489-520.

[41] Beck M, Michel B, Rybarczyk-Vigouret MC, Levêque D, Sordet C, Sibilia J, et al. Rheumatologists' perceptions of biosimilar medicines prescription: findings from a French web-based survey. BioDrugs 2016;30(6):585-92. 